\title{
Pre-Closure Investigation into the Impacts of Humic Injection Experiments on the South Oyster Field Research Site
}

\author{
John F. McCarthy \\ Department of Earth and Planetary Sciences \\ University of Tennessee, Knoxville, Tennessee
}

\section{GOALS AND OBJECTIVES}

The final research experiment conducted at the South Oyster Focus Area (SOFA) had the goal of evaluating the effect of organic amendments on the bioreductive processes of experimentally injected iron-reducing microbiota. A total of 20-g of humic substances were injected into the aquifer, representing the humic mass from several hundred liters of a peat-derived humic-rich groundwater that was concentrated using reverse osmosis (Sun et al. 1995). The humic groundwater was obtained from well E-0-D of the Kitty Hawk Woods Humic Reference Site. The chemical composition of the humic injection solution contrasts strongly with that of the autochthonous dissolved organic matter (DOM) in the Oyster groundwater. The humic injection solution was highly colored and its composition can be generally characterized as being predominantly large molecular weight, hydrophobic and rich in aromatic groups. In contrast, the colorless groundwater DOM in sandy coastal aquifers is low molecular weight, and hydrophilic (McCarthy et al. 1993; 1996). The chemical properties of the aquifer were altered by the introduction of a large volume $(1350 \mathrm{~L})$ of humic matter that was not only very different in chemical composition and properties, but also 10-fold higher in concentration than the autochthonous DOM.

A closure plan for SOFA was being implemented to assess the impacts of a series of experimental injections of microorganisms, tracers and chemical amendments on the chemical and physical properties of the aquifer. This report presents the results of environmental monitoring of humic substances and groundwater DOM that was identified as a requirement of the site closure plan. The goal of the research was to determine whether the DOM in the groundwater at, and downgradient from, the injection sites have returned to a pre-injection "baseline" conditions with respect to the concentration and chemical composition of the DOM. Return to "baseline" condition is mandated by the VaDEQ Anti-Degradation Policy for Groundwater specifying "natural quality shall be maintained for all constituents", and Research Application submitted to TNC which commits DOE to return the site to the "in situ" chemical conditions present before the experiments.

For clarity, the humic solution injected during the experiment will be referred to as "humic injection solution." The term "DOM" will refer to the organic material recovered in the groundwater, which includes the autochthonous groundwater DOM as well as any of the humic injection solution remaining in the groundwater.

Specific objectives include: 
- Monitor the DOM concentrations in groundwater over time at the injection wells and at sampling locations within the potential downgradient plume of the injected tracers.

- Evaluate the chemical composition of the DOM to determine whether the injection experiment had an impact of the chemical properties of the aquifer.

- Develop a process-level understanding of the recovery of the system to provide confidence that the monitoring data is representative of the long-term fate of the injected humics.

- Consolidate and analyze data for inclusion into the Oyster site closure report, and provide data to TNC.

\section{METHODS}

The concentration of DOM in the injection solution and in groundwater retrieved from sampling wells was measured using a Shimadzu TOC-V total organic carbon analyzer. Samples were acidified to $\mathrm{pH} 2$ and purged to remove inorganic carbon prior to analysis of the organic carbon. The DOM concentrations are reported as the level of total organic carbon (TOC), expressed as mg-carbon $\mathrm{L}^{-1}$. The aromatic content of the humics was estimated by measuring the UV-absorptivity at $270 \mathrm{~nm}\left(\mathrm{~A}_{270}\right.$; absorbance at 270 nanometers normalizing to the TOC concentration; (Traina et al. 1989). The composition of the humic material in the injection solution and groundwater was further characterized using XAD-8 fractionation (Leenheer 1981), which quantifies the relative abundance of three major chemical fractions: the total hydrophilic fraction, the hydrophobic acid fraction and the hydrophobic neutral fraction.

To increase confidence that the monitoring data is representative of the long-term fate of the injected humics, a column-scale transport experiment was conducted to simulate the field-scale humic injection. These data provide a process-level understanding of the recovery of the system. A glass column $(10.2-\mathrm{cm}$ long and 1.6-cm diameter) was filled with sediment core material from a depth equivalent to Port 11 of well S10. The core material was obtained prior to the humic injection experiments. The column was saturated with water flowing at rate of approximately $0.25 \mathrm{~m} \mathrm{~d}^{-1}$ from the bottom of the column to the top. After several days, the input source was changed to a solution of humic material from the same source as that used in the SOFA humic injection experiments. The humic input solution contained ${ }^{3} \mathrm{H}_{2} \mathrm{O}$ as a conservative tracer of water flow through the column. Approximately 30 pore volumes of the humic solution were injected through the column before the input solution was returned to organic-free water. The output solution was sampled with a fraction collector and the organic carbon concentration and UV-absorptivity at $270 \mathrm{~nm}$ measured as described above. Tritium levels were measured using liquid scintillation counting.

\section{RESUlTS AND DISCUSSION}




\section{DOM Concentration History during the Injection Experiment}

The field experiment injected a pulse of a humic solution at a concentration of approximately $7 \mathrm{mg}-\mathrm{C} \mathrm{L}^{-1}$. Groundwater recovered from the MLS injection ports following the injection showed a rapid decline in DOM levels with a few days of the

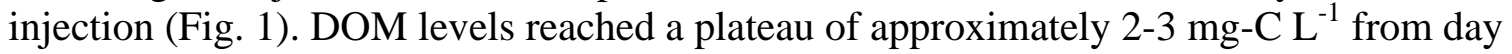
5 to 18 .

\section{Post-Injection Monitoring}

DOM was analyzed at 6 sampling locations that corresponded to three categories of potential impact from the humic experiments. One location was upgradient of the injection wells (SO-M1). Two locations were wells that had received humic injections (SO-S1 and -S10). Two monitoring wells were a transect perpendicular to the flow field and approximately 10-m downgradient of the injection wells (SO-M2, and -M3). The final sampling well was approximately 20-m downgradient of the humic injection wells (SO-B3).

The monitoring was conducted monthly from January 2002 to January 2003.

\section{DOM Concentrations in Groundwater}

DOM concentrations were constant over the 13 month monitoring period for all the wells that did not receive the humic injections (Fig. 2). Mean concentrations were 0.76 $\pm 0.16 \mathrm{mg}-\mathrm{C} \mathrm{L} \mathrm{L}^{-1}$. DOM concentrations in the humic injection wells were approximately the same as in the non-injected wells from January-August, 2002, but the DOC levels in the injection wells (SO-S1 and -S10) increased in late summer and early autumn. In December 2002 and January 2003, DOM levels in the humic injection wells dropped to levels comparable to the non-injected wells. The mean concentration of the two humic injection wells over the 13 month monitoring period was $1.24+0.66 \mathrm{mg}^{-\mathrm{C} \mathrm{L}^{-1}}$. The higher levels in the humic injection wells may have been the result of increased microbial utilization of adsorbed humics during the warmer months.

In summary, the DOM levels in the SOFA site had returned to stable baseline conditions for the 13 month monitoring period. Although there were brief periods of higher DOM levels in the humic injection wells, this effect was spatially limited and did not impact the rest of the site.

\section{Chemical Composition of DOM in Groundwater}

The time course of change in the chemical composition of the DOM was evaluated based on the aromatic content of the humics as expressed by the $A_{270}$ of the groundwater samples (Fig. 3). The $A_{270}$ values for all wells remained in the same range, and there was no statistical difference between the uninjected and humic-injected wells ( $p>0.05$, based on a single factor analysis of variance). Throughout the monitoring period, the $A_{270}$ values were far below those of the humic injection solution.

The chemical composition of the DOM was further evaluated by XAD-8 fractionation of the groundwater at two sampling times corresponding to the winter (February 2002) and early summer (May 2002). Results (Fig. 4) are presented as the means ( \pm standard deviations) of the fractional composition for the two humic injection wells and the four wells that did not receive the humic injections ((referred to as 
"control" in Fig. 4). The humic injection solution is dominated by the hydrophobic acid fraction. In contrast, the groundwater is predominantly hydrophilic. Furthermore, both the humic-injected and the uninjected wells showed a similar composition for both sampling periods,

Thus, the chemical composition of the groundwater DOM was not impacted by the humic injection experiment.

\section{Column-Scale Humic Transport Experiment}

The humics were strongly retarded relative to the rate of water movement, as revealed by differences in the breakthrough curves for DOM and the ${ }^{3} \mathrm{H}$-tracer (Fig. 5). The extensive tailing of the ascending limb of the DOM breakthrough curve reflects the adsorption of the humics to the aquifer sediments. It required more than 30 pore volumes of the injection solution before the DOM levels exiting the column approached that of the input solution. It should be noted that the concentration of the humic solution in the

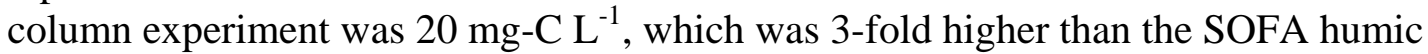
injection solution. It would have taken a much longer injection to saturate all the humic binding sites on the sediments if the input concentration were as low as during the field experiment (Dunnivant et al. 1992).

When the input solution was switched back to organic-free water, the DOM concentration in the column effluent dropped almost immediately, indicating that the humics adsorbed to the sediment did not desorb to any appreciable extent.

The results are similar to those reported for other studies of DOM transport (Dunnivant et al. 1992; McCarthy et al. 1993; 1996; Gu et al. 1996), and are consistent with the observed rapid decline in DOM levels immediately after the humic injection (Fig. 1).

The column experiment also demonstrated the preferential adsorption of hydrophobic, aromatic-rich components of the injected humics, as evidenced by the gradual increase in the $A_{270}$ values of the DOM eluting from the column. Recall that the $\mathrm{A}_{270}$ values are normalized to the DOM concentration in the sample, and are thus unrelated to the changes in the DOM concentrations. The low values $A_{270}$ early in the breakthrough curve indicate that almost all of the UV-absorbing organic matter was removed during transport through the sediment. As humic inputs continued, some of the humic binding sites became saturated, allowing more of the UV-absorbing humic components to reach the end of the column. This result is consistent with the field observations that the $A_{270}$ values in the groundwater were far below that of the humic injection solution (Fig. 3). Preferential adsorption of the UV-absorbing hydrophobic, aromatic humic moieties is also consistent with the marked differences in the XAD-8 fractionation results for the humic injection source and the groundwater DOM (Fig. 4).

The results of the column transport experiment provide process-level understanding that is consistent with the patterns observed in the closure monitoring of the SOFA groundwater. The injected humics have a high affinity for sorbing to the aquifer sediments, that adsorption is largely irreversible, and hydrophobic, aromatic-rich humic moieties are preferentially adsorbed. 


\section{SUMMARY AND CONCLUSIONS}

The potential impact of the humic injection experiments at the SOFA site were evaluated by determining the changes in DOM levels during the experiment, by 13 months of closure monitoring, and through a column-scale experiment to confirm that field observations were reasonable and consistent with processes observed under controlled laboratory conditions. Results demonstrated that the injected humics were retained within a very limited area in the immediate vicinity of the injection wells. The similarity in concentration and chemical composition of the DOM in wells upgradient and downgradient of the injection wells confirm that SOFA groundwater is fully restored to the "in situ" chemical conditions present before the experiments.

\section{Literature Cited}

McCarthy, J. F., B. Gu, L. Liang, J. Mas-Pla, T. M. Williams and T.-C. J. Yeh. 1996. Field tracers tests on the mobility of natural organic matter in a sandy aquifer. Water Resources Res. 32(5): 1223-1228.

McCarthy, J. F., T. M. Williams, L. Liang, P. M. Jardine, A. V. Palumbo, L. W. Jolley, L. W. Cooper, and D. L. Taylor. 1993. Mobility of natural organic matter in a sandy aquifer. Environ. Sci. Technol., 27:667-676.

Gu, B., T. Mehlhorn, L. Liang and J. F. McCarthy. 1996. Competitive adsorption, displacement, and transport of organic matter on iron oxide: II. Displacement and transport. Geochim. Cosmochim. Acta. 60:2977-2992.

Gu, B., J. Schmitt, Z. Chen, L. Liang and J. F. McCarthy. 1994. Adsorption-desorption of natural organic matter on iron-oxide: Mechanisms and models. Environ. Sci. Technol. 28:38-46.

Dunnivant, F. M., P. M. Jardine, D. L. Taylor, and J. F. McCarthy. 1992. Transport of naturally-occurring dissolved organic carbon in laboratory columns containing aquifer material. Soil Sci. Soc. Amer. J. 56: 437-443.

Sun L., Perdue E. M., and McCarthy J. F. 1995. Using reverse-osmosis to obtain organicmatter from surface and ground waters. Water Research 29(6): 1471-1477

Traina, S. J., J. Novak, and N.E. Smeck. 1989. An ultraviolet absorbance method of estimating the percent aromatic carbon content of humic acids. J. Environ. Qual. 19(1): 151-153. 


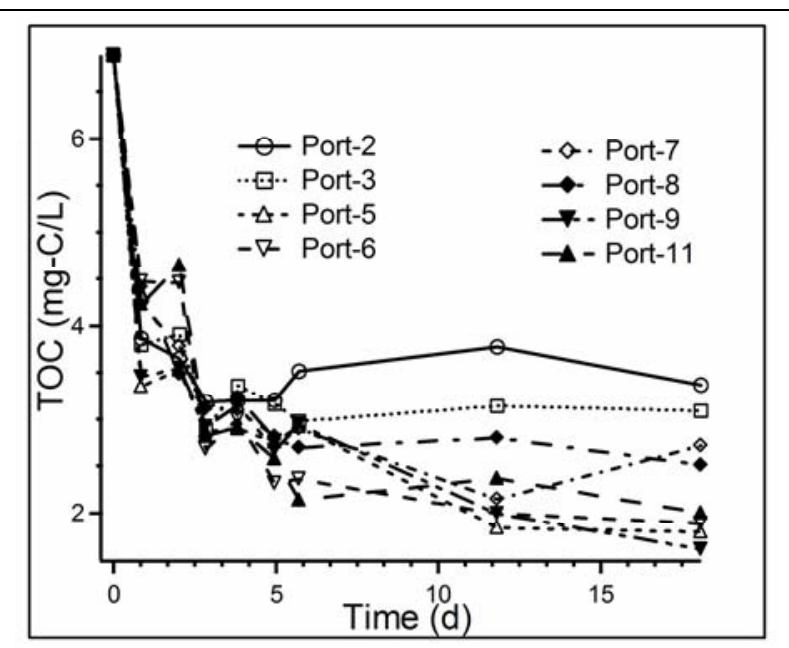

Fig. 1. Time course of DOC recovered from multilevel sampling ports in well S10 following injection of the humic solution at time zero.

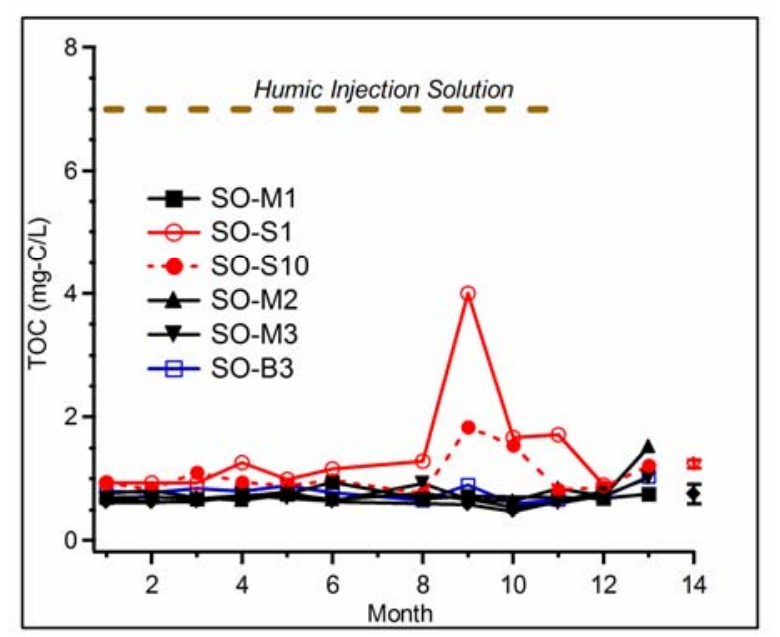

Fig. 2. Time course of changes in TOC concentrations in groundwater from the monitoring wells. The means $( \pm$ standard deviation) for the control and injected wells are shown to the right. The $A_{270}$ of the humics injected into wells S1 and S10 are shown above. 


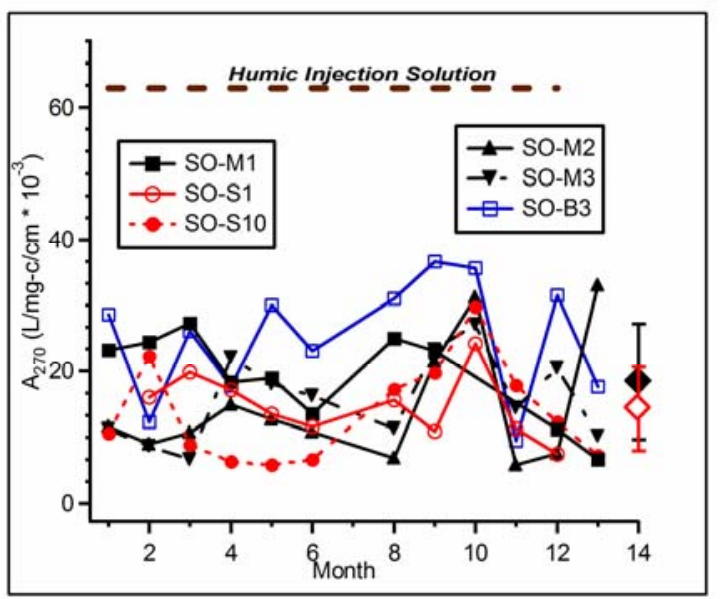

Fig. 3. Time course of changes in $A_{270}$ in groundwater from the monitoring wells. The means ( \pm standard deviation) for the control and injected wells are shown to the right. The $\mathrm{A}_{270}$ of the humics injected into wells S1 and S10 are shown above.

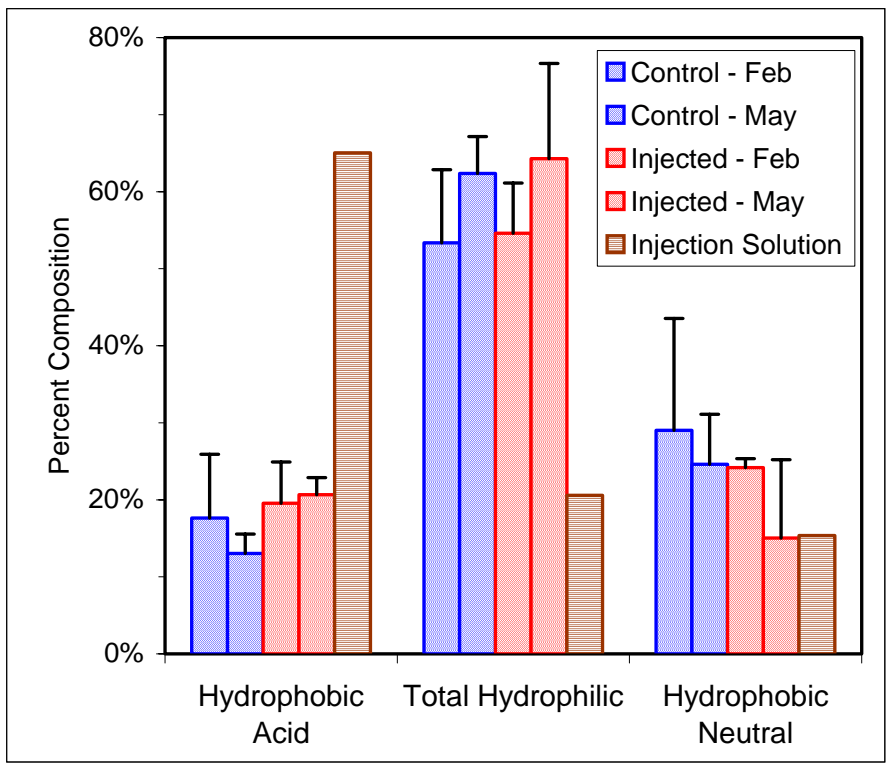

Fig. 4. Distribution of groundwater DOC into XAD-8 fractions at two sampling times (February and May, 2002). The mean and standard deviation of all the sampling sites at each sampling time are shown. The fractionation result for the humic solution injected into wells S1 and S10 is also shown. 


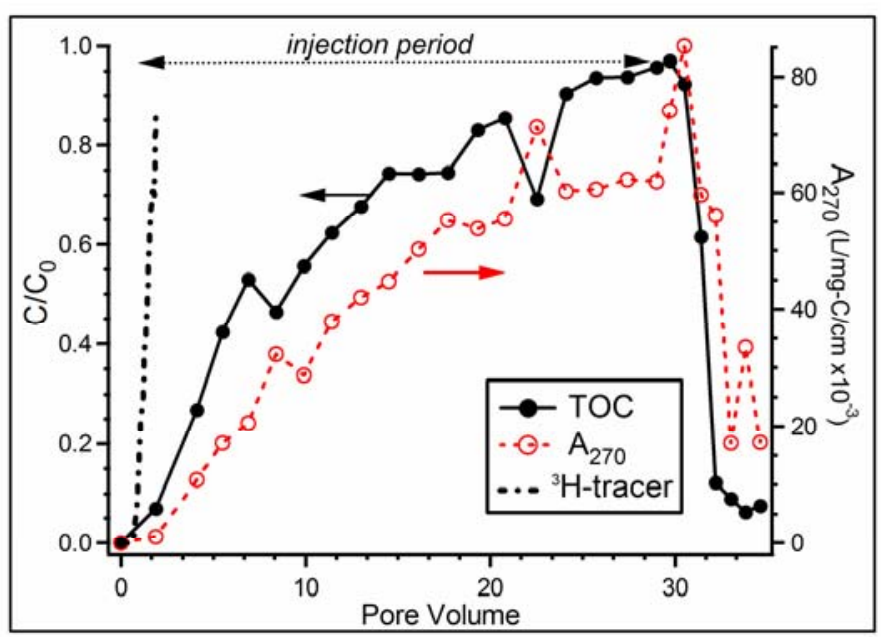

Fig. 5. Breakthrough curves for the humic solution injected into a laboratory column packed with sand from Port 11 of well S10. The TOC and tracer are shown in relative concentration (left axis). The change in $A_{270}$ is shown on the right axis. 